\title{
A clinicopathological study of episomal papillomavirus infection of the human placenta and pregnancy complications
}

Tania L Slatter ${ }^{1}$, Natalie GLY Hung ${ }^{2}$, William M Clow ${ }^{3}$, Janice A Royds ${ }^{1}$, Celia J Devenish ${ }^{3}$ and Noelyn A Hung ${ }^{1}$

${ }^{1}$ Department of Pathology, Dunedin School of Medicine, University of Otago, Dunedin, New Zealand; ${ }^{2}$ Kings College London, Strand, London, UK and ${ }^{3}$ Women's and Children's Health, Dunedin School of Medicine, University of Otago, Dunedin, New Zealand

\begin{abstract}
Viral infections are known to adversely affect pregnancy, but scant attention has been given to human papilloma virus (HPV) infection. We aimed to determine the molecular and histopathological features of placental HPV infection, in association with pregnancy complications including fetal growth restriction, pre-maturity, pre-eclampsia, and diabetes. Three hundred and thirty-nine placentae were selected based on the presence or absence of pregnancy complications. Five independent methods were used to identify HPV in the placenta, namely, immunohistochemistry for L1 viral capsid, in situ hybridization to high-risk HPV DNA, PCR, western blotting, and transmission electron microscopy. Pregnancy complications and uterine cervical smear screening results were correlated with placental HPV histopathology. In this study, which was deliberately biased towards complications, HPV was found in the decidua of $75 \%$ of placentae $(253 / 339)$ and was statistically associated with histological acute chorioamnionitis $(P<0.05)$. In $14 \%(35 / 253)$ of the HPV positive cases, HPV L1 immunoreactivity also occurred in the villous trophoblast where it was associated with a lymphohistiocytic villitis (HPV-LHV), and was exclusively of high-risk HPV type. HPV-LHV significantly associated with fetal growth restriction, preterm delivery, and pre-eclampsia (all $P<0.05$ ). All cases of pre-eclampsia (20/20) in our cohort had high-risk placental HPV. A further 55 cases $(22 \%, 55 / 253)$ of HPV positive placentae had minimal villous trophoblast HPV L1 immunoreactivity, but a sclerosing pauci-immune villitis, statistically associated with diabetes $(49.1 \%, 27 / 55, P<0.05)$. For women with placental HPV, 33\% (69/207) had an HPV-related positive smear result before pregnancy compared with $(9.4 \% 8 / 85)$ of women with HPV-negative placentae $(P=0.0001)$. Our findings support further investigations to determine if vaccination of women and men will improve pregnancy outcomes.
\end{abstract}

Modern Pathology (2015) 28, 1369-1382; doi:10.1038/modpathol.2015.88; published online 21 August 2015

In the immune and hormonal modulated milieu of pregnancy, viruses are well known to infect the placenta, developing fetus, and neonate. The most common and important neoplastic driver of the lower uterine tract, human papillomavirus (HPV), ${ }^{1}$ has been detected in the uterine cervix of $15-25 \%$ of pregnant women ${ }^{2-6}$ and a cervical HPV infection during pregnancy has been associated with a higher incidence of spontaneous abortions, ${ }^{7-9}$ premature rupture of the membranes, ${ }^{10}$ spontaneous preterm

Correspondence: Dr N Hung, Pathogenesis Group, Department of Pathology, Dunedin School of Medicine, University of Otago, PO Box 1777, Dunedin 9016, New Zealand.

E-mail: noelyn.hung@otago.ac.nz

Received 15 February 2015; revised 22 June 2015; accepted 23 June 2015; published online 21 August 2015 labor, ${ }^{11,12}$ pre-eclampsia, ${ }^{13}$ and placental 'villitis' not otherwise specified. ${ }^{12}$ HPV DNA has been detected in the placenta and amniotic fluid. ${ }^{7,11,14-17}$ HPV strains $6,11,16,18$, and 31 have been shown to replicate in trophoblast cell lines, ${ }^{18-20}$ where HPV infection decreased trophoblast number and trophoblast-endometrial cell adhesion in vitro. ${ }^{19,20}$

We investigated for the presence of HPV in the placenta and carried out a histopathological and molecular cross-sectional study of 339 placentae from complicated and uncomplicated pregnancies. We sought to determine if the HPV infection occurred in the placenta, the histopathological features, the correlation with uterine cervical smear history, and if it could contribute to pregnancy complications. 


\section{Materials and methods}

\section{Participants}

We obtained singleton placentae $(n=339)$ from the Otago Placenta Study, which comprises 720 placentae collected during 2009-2014 [23]. Parent/s provided signed informed consent and ethical approval was obtained from the New Zealand Health and Disabilities Multiregional Ethics and Lower Regional South Ethics Committees (LRS/09/09/038).

The sample was socioeconomically diverse, and participants were a mixture of urban and rural women with low- and high-risk pregnancies recruited from prenatal clinics and at the time of delivery, largely on a convenience basis. Cases were selected from women not vaccinated against HPV, and for whom clinical data (maternal age, cigarette smoking $<10$ cigarettes/ day, medical history, body weight and height (first trimester), index pregnancy data (parity, gravidity, gestational age, obstetric history, fetal birth weight, and fetal outcome) and placental resources (tissue sections, fresh frozen tissue, macroscopic and microscopic descriptions) were complete. For all cases, including those of idiopathic fetal growth restriction (FGR) and fetal demise, individuals with specific medical conditions (except for pre-eclampsia and diabetes) were excluded. These medical conditions included fetal anomalies (following first trimester combined screening and/or subsequent chromosomal anomaly confirmation, abnormal fetal anatomy scan), known current infection (cervical swab positive for Chlamydia trachomatis or Neisseria gonorrhoeae DNA, vaginal swab positive for vaginosis, fungi, or Trichomonas vaginalis) or positive maternal serology (HIV, syphilis by ELISA immunoassay, hepatitis B antigen, toxoplasmosis antibody and avidity, and rubella IgG antibody assessment) and maternal autoimmune diseases, were excluded $(n=132)$. Reasons for non-inclusion also included uncollated or missing clinical data at the time of the study or unprepared tissue samples at the time of the study $(n=249)$. Supplementary cases outside the cohort were also investigated for HPV infection using the same methods. These comprised three examples of nongravid endometrial and fallopian tube tissues (from endometrial cancer cases).

FGR was defined as weight $\leq 5$ th centile for gestational age, as determined by the GROW-centile calculator with permission from the Perinatal Institute (http://www.perinatal.org.uk). For gestational ages $<24$ weeks, estimates of early fetal growth centiles were taken from those reported by Philips et al. for the Australian population. ${ }^{21}$ Prematurity was defined as a gestation period under 37 weeks. Pre-eclampsia was clinically diagnosed according to SOMANZ guidelines (https://somanz. org). Cervical smear histories were collected from the New Zealand National Cervical Screening Programme Register.

\section{Procedures}

A trained examiner, blinded to the clinical history, assessed fresh, fixed, or refrigerated placentae (within $24 \mathrm{~h}$ of delivery) using standard pathologic techniques. Eight standard sections were dissected per placenta and consisted of transmural placental sections within $50 \mathrm{~mm}$ of the umbilical insertion. In addition, tissue samples were taken from 10 placentae to investigate the effect of delayed fixation and prolonged fixation in 10\% neutral buffered formalin before processing to paraffin wax. A perinatal pathologist examined haematoxylin and eosin (H\&E) stained sections that were prepared according to standard procedures. The pathologist was unaware of maternal history, pregnancy complications, delivery circumstances, and ethnicity associated with each placenta, but informed of the gestational age (to assist in the assessment). Histopathological chorioamnionitis was assessed according to the criteria of Holzman et al. $^{22}$ and low maternal/high fetal, high maternal/low fetal, and high-maternal/high-fetal response categories were recorded as clinically significant acute chorioamnionitis. Any further histopathological abnormalities, such as necrotizing deciduitis, were descriptively recorded. Smoking history was correlated with the DNA-damage pattern in the placenta, ${ }^{23}$ to ensure that there was minimal effect of undeclared smoking on measured complications.

\section{Immunohistochemistry}

The L1 HPV-viral capsid protein (clone K1H8, Dako, Glostrup, Denmark, which detects HPV expressed among high-risk types 16, 18, 31, 33, 51, 52, 56 and 58, and low-risk types 6, 11, and 42. ${ }^{24,25} \gamma \mathrm{H} 2 \mathrm{AX}$ (Abcam, Cambridge, UK), ${ }^{23}$ CD163 (SP96, Abcam, Cambridge, UK), and p53 (DO-7, Dako, Glostrup, Denmark) antibodies were applied to transmural placental tissue. Screening for the presence of L1 viral capsid protein by immunohistochemistry (IHC) has an acceptable sensitivity and specificity to determine HPV infection in cervical and other tissues. ${ }^{24,25}$ The dilution of antibody used was that according to the manufacturers' instructions (Dako, Glostrup, Denmark and Abcam, Cambridge, UK). HPV, $\gamma \mathrm{H} 2 \mathrm{AX}$, and p53-positive cells were detected using the EnVision Dual Link (Dako, Glostrup, Denmark) and $\mathrm{DAB}$ methods. Cells were imaged using light microscopy (DM 2000 microscope, DFC 295 camera, and Application Suite software, version 3.5.0, Leica, Solms, Germany). IHC sections were screened separately by two investigators and finally re-examined in concert with the H\&E sections. Six or more positive cells of any placental cellular type on a transmural section determined a positive HPV L1 capsid IHC result. For negative controls, isotype control serum was used in place of primary antibodies.

\section{Western Blotting}

The method of Hass and Sohn ${ }^{26}$ was used to prepare protein samples from $300 \mathrm{mg}$ of maternal surface 
region (decidua) frozen tissue stored at $-80^{\circ} \mathrm{C}$ for 36 placentae: $15 \mathrm{HPV}$-negative cases, and 21 cases typed as HPV positive (15 HPV-decidua cases, and 6 HPV-LHV cases). The Qubit Protein Assay Kit (Life Technologies, Carlsbad, CA, USA) was used to quantify protein concentration. Approximately $100 \mu \mathrm{g}$ of each protein lysate was separated on a 4-12\% NuPAGE Novex Bis-Tris Mini Gels (Life Technologies) and transferred to a PVDF membrane. Blots were incubated with anti-HPV (K1H8; 1 in 500 dilution) or beta-actin (ab82618, Abcam; 1 in 7000 dilution). Alkaline phosphatase conjugated secondary antibodies were detected using the WesternBreeze Chemiluminescent Kit detection system according to the manufacturer's instructions (Life Technologies). Images were captured on X-ray film.

\section{Chromogenic In Situ Hybridization (CISH)}

HPV DNA was detected using the GenPoint HPV DNA Probe cocktail (identifies 13 high-risk HPV types: $16,18,31,33,35,39,45,51,52,56,58,59$, and 68 ) and the GenPoint Tyramide Signal Amplification system according to the manufacturer's instructions with one modification (the biotinyl tyramide solution was added to each slide for five instead of 15 min) (Dako, Glostrup, Denmark). Cells were imaged using light microscopy. The pattern of positivity was assessed according to Birner et al..$^{25}$ As negative controls placental tissue from cases determined as HPV positive by in situ hybridization were incubated with the negative control, plasmid only DNA Biotinylated Probe, (Dako, Glostrup, Denmark) to ensure negative staining occurred in the absence of the HPV DNA probe.

\section{HPV PCR}

HPV was identified using the Human Papillomavirus PCR Typing Set (Takara Bio, Otsu, Japan) which identifies HPV types 6, 11, 16, 18, 33, 52b, and 58 . Genomic DNA was extracted from $300 \mathrm{mg}$ of frozen placental tissue (decidual region) and used with the kit according to the manufacturer's instructions (Takara Bio, Otsu, Japan).

\section{Transmission Electron Microscopy}

Transmission electron microscopy analysis was performed using a standard technique. Samples were fixed in $3 \%$ glutaraldehyde in $0.1 \mathrm{M}$ cacodylate buffer immediately following delivery of the placenta. Samples were then washed thrice with $0.1 \mathrm{M}$ cacodylate buffer and placed in 1\% osmium tetroxide in $0.1 \mathrm{M}$ cacodylate buffer. Samples were en bloc stained in 1\% uranyl acetate in double distilled water, dehydrated and embedded in EmBed 812 (Electron Microscopy Sciences, USA). Semi-thin sections $(1 \mu \mathrm{m})$ were cut and examined to determine the region of interest. This was followed by ultrathin sectioning $(100 \mathrm{~nm})$ and mounting of sections on formvar-coated copper slot grids. Ultrathin sections were contrasted with uranyl acetate and lead citrate, and viewed with a Philips CM100 transmission electron microscope (Philips/FEI, Eindhoven, the Netherlands) operating at $100 \mathrm{kV}$. Images were captured using a MegaView 3 camera (Soft Imaging System GmbH, Münster, Germany).

\section{Validation}

The IHC and CISH methods had a good specificity toward HPV as evident from the use of positive and negative control tissues (Figure 1). The HPV L1 capsid protein and HPV DNA by CISH was detected in the dysplastic uterine cervix nuclei (Figure 1, photomicrographs a and b). The HPV antibody used was specific with western blots of HPV positive tissues showing a single band of $57 \mathrm{kDa}$ consistent with the size of the HPV L1 capsid protein (Figure 1, photomicrograph c). ${ }^{27}$ Electron microscopy was performed on a HPV positive placenta and revealed viral-like particles as illustrated in Figure 1, photomicrograph d, with a dense core, less dense 'spiked' capsule, and diameter between 50 and $60 \mathrm{~nm} .^{27,28}$ IHC and CISH staining was negative in tissues stained with control isotype sera (Figure 1, photomicrographs e and g) or the control plasmid DNA probe (Figure 1, photomicrographs $\mathrm{f}$ and h). Forty cases were selected for HPV confirmation by PCR: 12 HPV negative cases by IHC and CISH, $15 \mathrm{HPV}$ positive cases by IHC and CISH, and 13 HPV positive cases by IHC but negative for HPV by CISH. The PCR confirmed the presence of high-risk HPV types in all cases positive for HPV by IHC and CISH, low-risk HPV types in cases HPV positive for HPV by IHC but HPV negative by CISH, and no HPV was detected by PCR in placentae typed as negative for HPV by IHC and CISH.

\section{Statistical Analyses}

$\chi^{2}$ tests were used to compare differences between groups for categorical measures and one-way ANOVA for continuous measures. Associations are described as an odds ratio (OR) with a 95\% confidence interval. Statistical significance is indicated by a two-tailed $P$-value $<0.05$.

\section{Results}

\section{Participants}

The cohort comprised 251 term pregnancies and 88 preterm deliveries, and was predominately of European descent (90\%, 305/339), with thirteen Māori and Pacific Islanders, and five Chinese participants. Sixteen women identified as mixed ethnicity. 


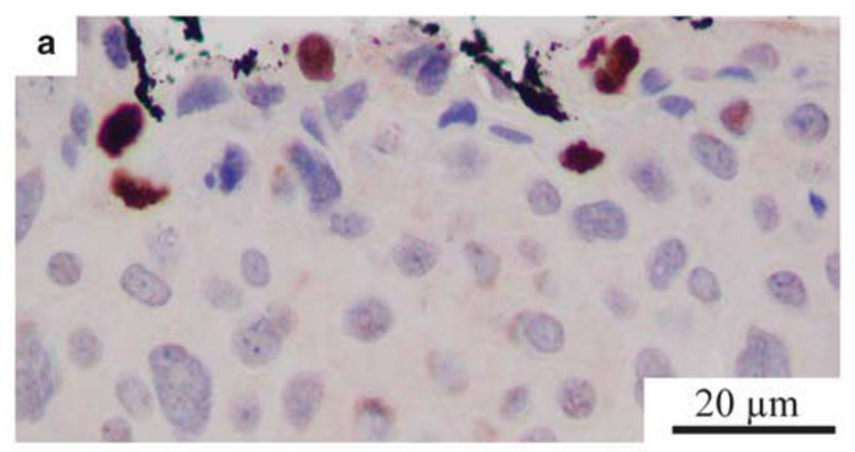

c
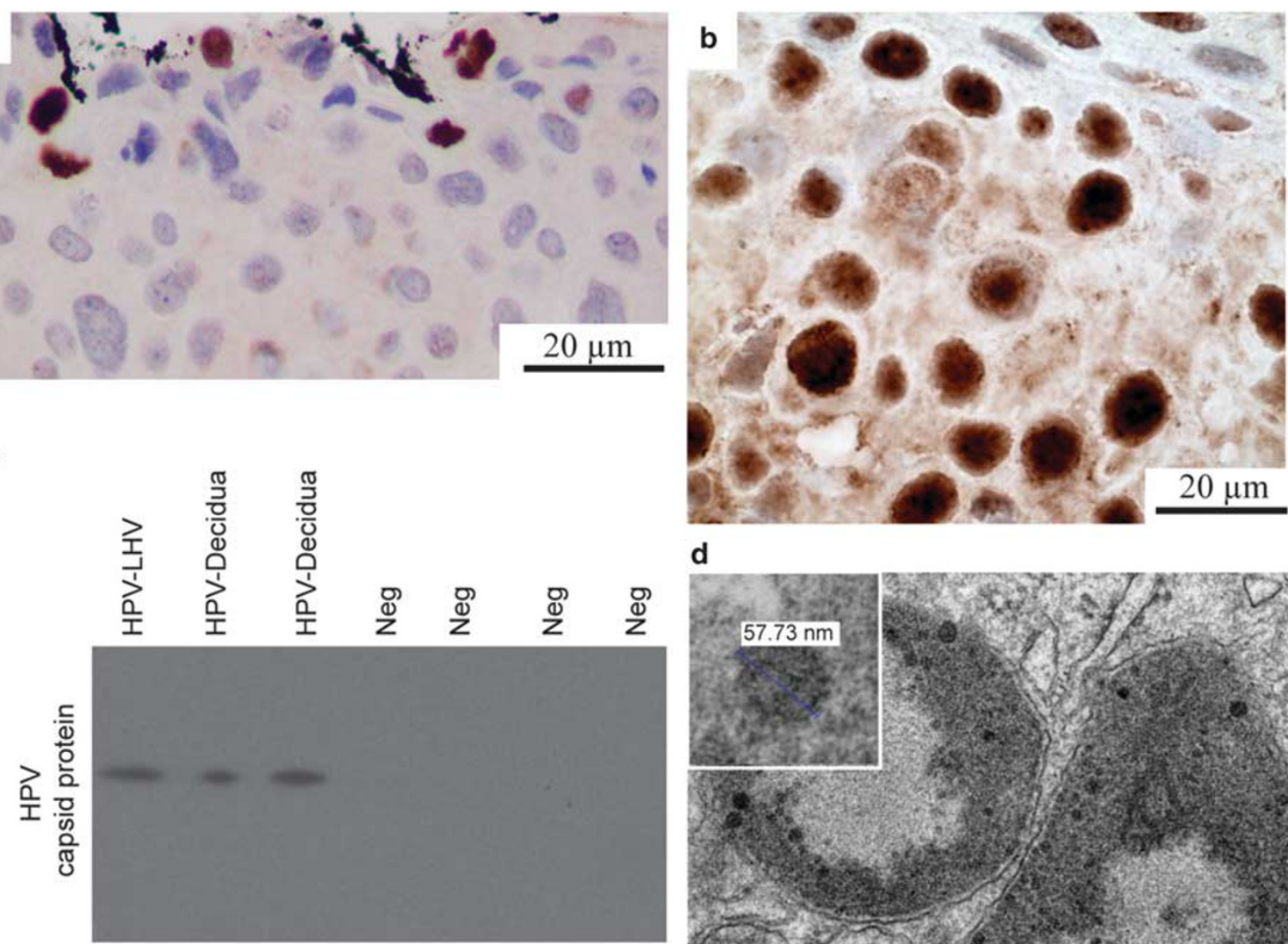

d

$\beta$-actin
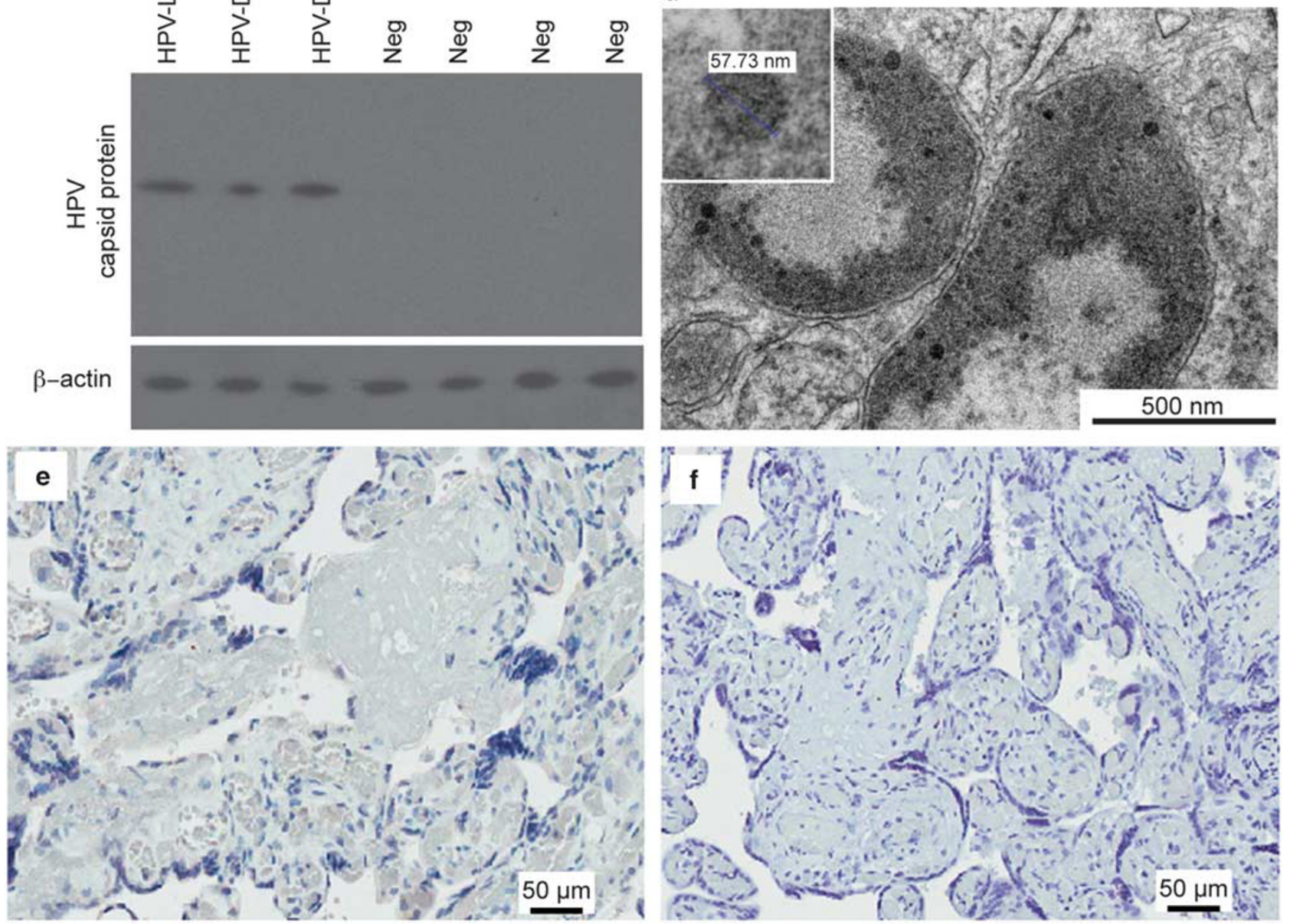

Figure 1 Validation of HPV IHC and CISH methods using control tissues. (a) HPV L1 capsid protein was detected using IHC in control cervical intraepithelial neoplasia grade three to illustrate nuclear staining. The differentiated superficial cell nuclei showed intense positive staining. (b) HPV DNA was detected using CISH in control cervical intraepithelial neoplasia grade 3 and highlighted nuclear positivity throughout the epithelium. (c) Blotting for the HPV L1 protein confirmed the presence of a single band $57 \mathrm{kDa}$ in size. Protein was extracted from placentae determined as HPV positive (HPV-LHV and HPV Decidua) or HPV negative (Neg) by IHC and separated using SDS-PAGE. The antibody used to detect HPV L1 by IHC was used to detect HPV in western blots. Beta-actin was used as a loading control. (d) Electron micrograph showing virallike particles within the cytoplasm. Insert, transmission electron micrograph at high power to illustrate a viral-like particle measuring $57.43 \mathrm{~nm}$ in diameter. (e) HPV L1 IHC negative isotype control in placental villi. Isotype control serum was incubated in placental tissue previously stained as HPV positive by IHC to illustrate negative staining in the absence of the HPV L1 protein antibody. (f) HPV DNA CISH negative control in placental villi. A probe toward plasmid DNA was added to placental tissue previously stained as HPV probe positive to illustrate negative staining in the villi in the absence of the probe toward HPV DNA. (g) HPV L1 IHC negative isotype control in decidua. Isotype control serum was incubated in placental tissue sections previously stained as HPV positive to illustrate negative staining in the decidua in the absence of the HPV L1 capsid protein antibody. (h) HPV DNA CISH negative control in decidua. A probe toward plasmid DNA was added to placental tissue previously stained as HPV probe positive to illustrate negative staining in the decidua in the absence of the probe toward HPV DNA. CISH, chromogenic in situ hybridization; HPV, human papilloma virus; IHC, immunohistochemistry; LHV, lymphohistiocytic villitis. 

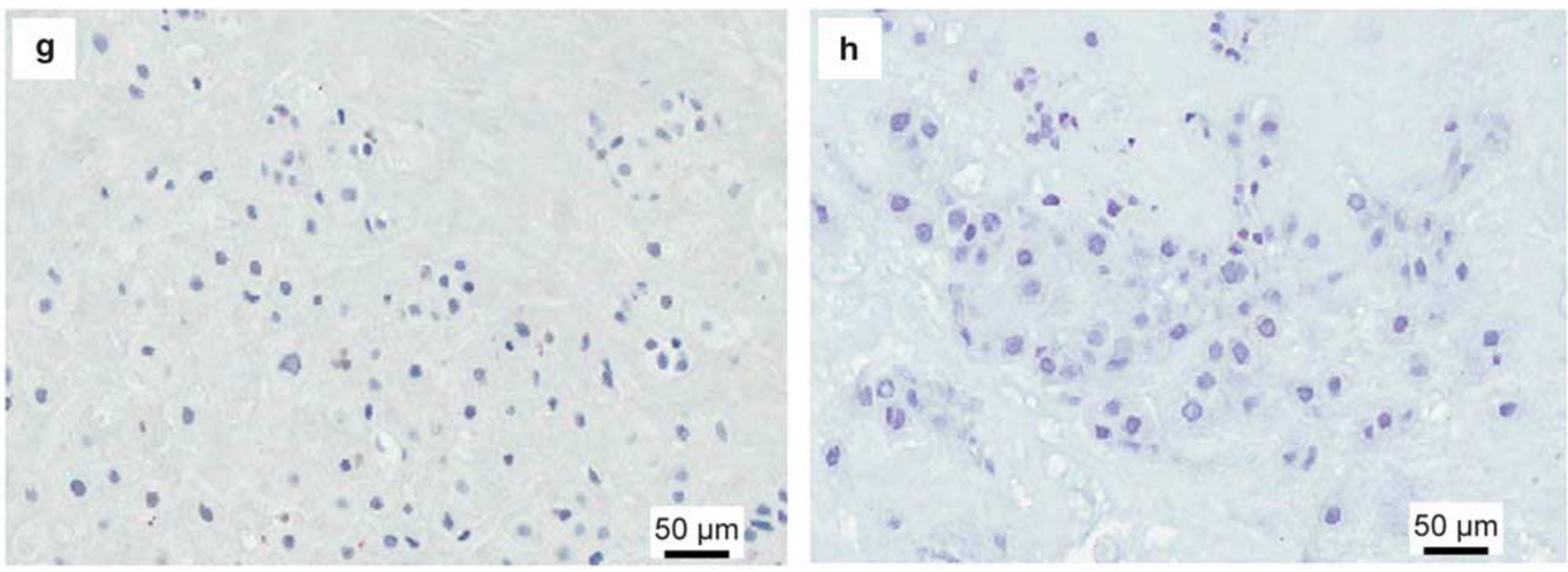

Figure 1 Continued.

Table 1 Cohort characteristics

\begin{tabular}{|c|c|c|c|c|c|c|c|c|c|c|}
\hline \multirow[b]{2}{*}{$\mathrm{N}=339$ total } & \multicolumn{2}{|c|}{ Preterm $(\mathrm{n}=88)$} & \multicolumn{2}{|c|}{ Term $(\mathrm{n}=251)$} & \multicolumn{2}{|c|}{$<5$ th $P G C(\mathrm{n}=72)$} & \multicolumn{2}{|c|}{$\begin{array}{c}G D M \text { and } T 1 D M \\
(\mathrm{n}=44)\end{array}$} & \multicolumn{2}{|c|}{$\begin{array}{l}\text { Pre-eclampsia } \\
\quad(\mathrm{n}=20)\end{array}$} \\
\hline & Mean & s.d. & Mean & s.d. & Mean & s.d. & Mean & s.d. & Mean & s.d. \\
\hline $\begin{array}{l}\text { Gestational age } \\
\text { (weeks) }\end{array}$ & 30.61 & 6.35 & 39.51 & 1.33 & 34.93 & 7.30 & 37.16 & 2.72 & 35.50 & 3.75 \\
\hline Maternal age (years) & 30.10 & 5.82 & 31.34 & 5.57 & 29.59 & 4.99 & 32.51 & 4.92 & 28.77 & 6.08 \\
\hline Maternal BMI & 26.67 & 6.10 & 26.17 & 6.07 & 25.88 & 6.19 & 30.72 & 9.07 & 28.76 & 6.91 \\
\hline \multirow{2}{*}{$\begin{array}{l}\text { Personalized fetal } \\
\text { growth centile }\end{array}$} & 31.64 & 33.26 & 36.60 & 29.75 & 1.72 & 1.72 & 60.08 & 37.97 & 30.90 & 30.09 \\
\hline & Median & $\begin{array}{l}\text { 25th-75th } \\
\text { percentile }\end{array}$ & Median & $\begin{array}{l}\text { 25th-75th } \\
\text { percentile }\end{array}$ & Median & $\begin{array}{l}\text { 25th-75th } \\
\text { percentile }\end{array}$ & Median & $\begin{array}{l}\text { 25th-75th } \\
\text { percentile }\end{array}$ & Median & $\begin{array}{l}\text { 25th-75th } \\
\text { percentile }\end{array}$ \\
\hline Maternal parity & 1 & $0-2$ & 1 & $0-1$ & 1 & $0-1$ & 1 & $1-2$ & 0 & $0-1$ \\
\hline Maternal gravidity & 2 & $1-4$ & 2 & $1-3$ & 2 & $1-3$ & 2 & $1-3$ & 1 & $1-3$ \\
\hline Complication & $\boldsymbol{N}$ & $\%$ & $N$ & $\%$ & $N$ & $\%$ & $N$ & $\%$ & $N$ & $\%$ \\
\hline $\begin{array}{l}\text { Antepartum } \\
\text { hemorrhage \% }\end{array}$ & 12 & $13.60 \%$ & 7 & $2.80 \%$ & 8 & $11.10 \%$ & 0 & $0.00 \%$ & 1 & $5.00 \%$ \\
\hline Preterm \% & 88 & $100.00 \%$ & 0 & $0.00 \%$ & 23 & $33.00 \%$ & 15 & $34.00 \%$ & 7 & $36.80 \%$ \\
\hline $\begin{array}{l}\text { Histological acute } \\
\text { chorioamnionitis }\end{array}$ & 8 & $9.10 \%$ & 17 & $6.80 \%$ & 8 & $11.10 \%$ & 0 & $0.00 \%$ & 0 & $0.00 \%$ \\
\hline
\end{tabular}

Abbreviations: BMI, body mass index; GDM, gestational diabetes mellitus; PGC, personalized fetal growth centile; T1DM, type 1 diabetes mellitus.

Gestational age ranged from 14 to 43 weeks, with a mean of 37.3 weeks, and median of 39 weeks. Cohort characteristics are presented in Table 1. Uncomplicated term pregnancies $(n=227)$ had personalized fetal growth greater than the fifth centile and delivery per vaginam or by elective Cesarean section. Complicated pregnancies included 88 cases of prematurity, 44 pregnancies from diabetic women (12 type 1 diabetes mellitus and 32 gestational diabetes cases), 20 cases of pre-eclampsia, and 72 cases of idiopathic FGR. As expected by design, gestational age was significantly lower in the preterm group, with personalized growth centiles lowest in the idiopathic FGR group, and highest in the diabetic group.

\section{HPV in the Placenta}

In our cohort, biased towards complications, $75 \%$ (253/339) of the placentae were positive for the HPV L1 capsid protein. Chromogenic in situ hybridization for 13 high-risk HPV types was performed on all placentae to confirm the presence of HPV and to determine the prevalence of high-risk HPV types. Of the 253 cases that were HPV L1 IHC positive, 197 were positive and 56 were negative for HPV high-risk DNA. Therefore most (78\%) of HPV positive placentae were positive for high-risk HPV types. Placentae positive by IHC but negative by CISH were likely to be infected with low-risk HPV types only. Of the 86 
cases that were HPV negative by IHC, 85 were negative by CISH, demonstrating a good correlation between the HPV IHC and HPV-CISH results. In the 232 placentae associated with pregnancy complications 83\% (192/232) were HPV positive compared with $57 \%$ (61/107) of placentae from uncomplicated pregnancies. Although HPV was found in a high percentage of complicated pregnancies it was also found in uncomplicated pregnancies suggesting HPV is not always pathogenic especially when infection is limited to the decidua.

\section{HPV Infection Occurs as Three Histopathological Patterns}

Three immunohistopathological patterns were identified in HPV positive placentae, termed HPVdecidua, HPV-lymphohistiocytic villitis (HPV-LHV), and HPV-sclerosing villitus (HPV-SV). The features of each histopathological group with regards to analysis by H\&E, HPV L1 IHC, HPV-CISH, CD163 IHC, p53 IHC, and gamma H2AX IHC are summarized in Table 2. High-risk HPV types predominated, and were found almost exclusively in HPV-LHV and HPV-SV groups.

\section{HPV Detection in the Decidua and Endometrium}

Placentae with decidua positive for HPV (163/253, $64 \%$ ) were largely unremarkable by H\&E assessment (Figure 2, photomicrographs a and b, Table 2). HPV L1 IHC and CISH identified HPV positive signals in the cytoplasm of decidua (Figure 2c and d, HPV L1 IHC, and HPV L1 HPV-CISH, respectively), associated with a DNA- damage/repair response (Figure 2, photomicrographs $\mathrm{e}$ and $\mathrm{f}$, gamma H2AX and p53 IHC respectively). A DNA-damage/ repair response has been previously described in papillomavirus infection. ${ }^{29}$ We did not observe $\gamma \mathrm{H} 2 \mathrm{AX}$ - and/or p53-positive cells in the decidua of HPV negative cases. However, the strongest signal for HPV was identified in the endometrial epithelium (Figure 3, photomicrograph a HPV L1 IHC), with both strong endometrial cell cytoplasmic and nuclear staining using HPV-CISH (Figure 3, photomicrographs b and c). Supplementary non-gravid endometrial cancer cases were examined and small areas of positive signal were identified in remnant non-dysplastic endometrium and fallopian tube epithelium Figure 3, photomicrographs d-g).

In the decidua both high and low-risk HPV types were detected, with high-risk types identified in the majority of cases.

\section{HPV Detection in Lymphohistiocytic Villitis}

We detected LHV in 14\% (35/253) of HPV positive cases, including cases with a pattern typical for villitis of unknown etiology (VUE). Although less frequent than HPV decidua, the additional presence of HPV-LHV was of greater clinical consequence (see below). The villitis was patchy with variable numbers of infiltrating villous lymphocytes (ranging from scant to abundant, Figure 4, photomicrograph a). The involved villi had perivillous fibrin embracing disintegrated syncytiotrophoblast (Figure 4, photomicrograph b). HPV-L1 capsid was detected in the syncytiotrophoblast and villous stromal cells (Figure 4, photomicrographs c and d) and gamma H2AX was detected in the villous stromal cells (Figure 4, photomicrograph e). High-risk HPV-DNA was found in a diffuse pattern in syncytiotrophoblast and stromal cells nuclei (Figure 4, photomicrograph f). High-risk HPV types predominated in LHV in that all cases designated HPV-LHV by L1 capsid IHC were also positive by HPV-CISH.

\section{HPV Detection in Sclerosing Villitis}

HPV-sclerosing villitis (Figure 5) was a characteristic feature in a further subset of cases $(55 / 253,22 \%$ ) and suggested an inflammatory resolution from

Table 2 H\&E and HPV molecular features of the HPV positive histopathological subgroups

\begin{tabular}{|c|c|c|}
\hline Diagnosis & Histopathological features & HPV L1 IHC and HPV-CISH \\
\hline HPV-decidua & $\begin{array}{l}\text { Unremarkable H\&E examination in most cases, or histological } \\
\text { acute necrotizing deciduitis }(6 \%) \\
\text { Host DNA damage /repair response }(\gamma \mathrm{H} 2 \mathrm{AX} \text { and p53 nuclear } \\
\text { response) }\end{array}$ & $\begin{array}{l}\text { HPV L1 IHC positive decidua and endometrium. } \\
\text { High-risk HPV types in } 66 \%(108 / 163) \\
\text { Low risk HPV types in } 34 \%(55 / 163)\end{array}$ \\
\hline $\begin{array}{l}\text { HPV-lympho- } \\
\text { histiocytic villitis }\end{array}$ & $\begin{array}{l}\text { Patchy loss of syncytiotrophoblast, perivillous fibrin } \\
\text { deposition, lymphohistiocytic inflammation (fulfills criteria } \\
\text { for villitis of unknown etiology). } \\
\text { Host DNA damage /repair response ( } \gamma \mathrm{H} 2 \mathrm{AX} \text { and p53 nuclear } \\
\text { response) }\end{array}$ & $\begin{array}{l}\text { HPV L1 IHC positive decidua and endometrium. } \\
\text { HPV L1 IHC positive syncytiotrophoblast areas } \\
\text { and cytotrophoblasts, villous stromal cells, } \\
\text { Hofbauer cells. } \\
\text { High-risk types in } 100 \%(35 / 35)\end{array}$ \\
\hline $\begin{array}{l}\text { HPV-sclerosing } \\
\text { villitis }\end{array}$ & $\begin{array}{l}\text { Few lymphocytes but increased numbers of CD163 positive } \\
\text { macrophages in villi, stromal fibrosis, perivillous, and } \\
\text { intravillous fibrin deposition. } \\
\text { Host DNA damage /repair response ( } \gamma \mathrm{H} 2 \mathrm{AX} \text { and p53 nuclear } \\
\text { response) }\end{array}$ & $\begin{array}{l}\text { HPV L1 IHC positive decidua and endometrium. } \\
\text { Minimal HPV L1 IHC positive villous trophoblast, } \\
\text { villous stromal cells, Hofbauer cells } \\
\text { High-risk types in } 98 \%(54 / 55) \\
\text { Low risk types in } 2 \%(1 / 55)\end{array}$ \\
\hline
\end{tabular}



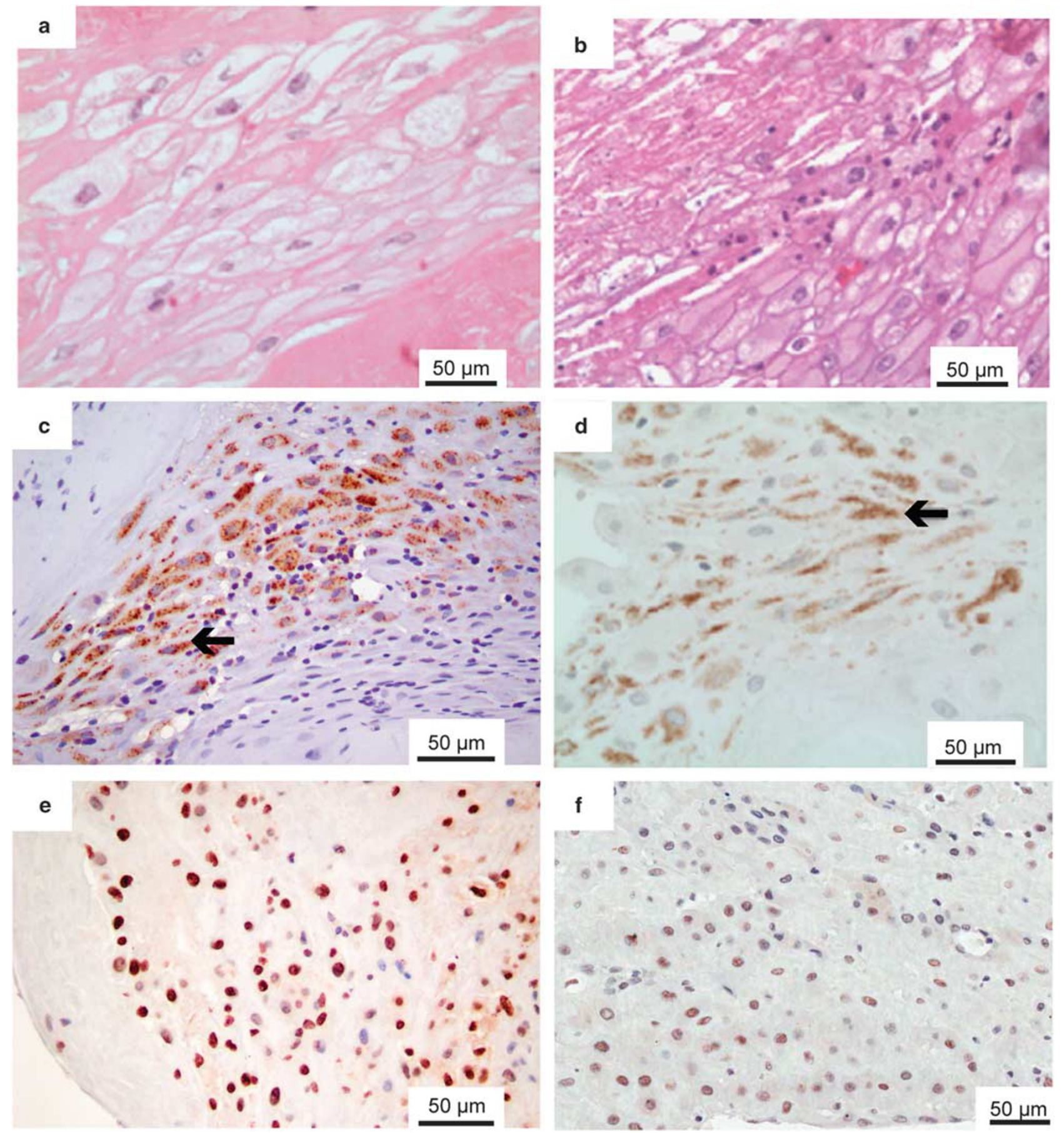

Figure 2 Histopathological and molecular features of HPV-decidua. (a) H\&E decidua to illustrate that the majority of cases had no inflammation. (b) H\&E decidua to illustrate occasional decidual degeneration and nuclear debris. (c) HPV L1 IHC decidua to illustrate HPV positivity in the decidual cell cytoplasm (arrow). (d) HPV DNA CISH decidua to illustrate HPV positivity within decidual cell cytoplasm (arrow). (e) Gamma H2AX IHC in HPV-decidua group to illustrate double strand DNA break positivity in decidual cell nuclei. (f) Scattered p53 positive nuclei using IHC in HPV-decidua group to illustrate positivity in decidual cell nuclei. CISH, chromogenic in situ hybridization; H\&E, hematoxylin and eosin stain; HPV, human papilloma virus; IHC, immunohistochemistry.

HPV-LHV to scarring. HPV-SV was associated with partially or completely sclerosed villi (Figure 5, photomicrographs a, c, and f). HPV-SV cases were lymphocyte-poor with few HPV positive villous syncytiotrophoblast areas (following examination of at least four sections). Compared with HPV negative samples, Hofbauer and stellate histiocytes were prominent within the villous stroma of sclerosing HPV-SV samples, and were identified as M2 phenotype by CD163-IHC (Figure 5, photomicrograph f, black arrow). HPV-L1 IHC identified HPV-positive villous stromal cells (Figure 5, photomicrographs b 

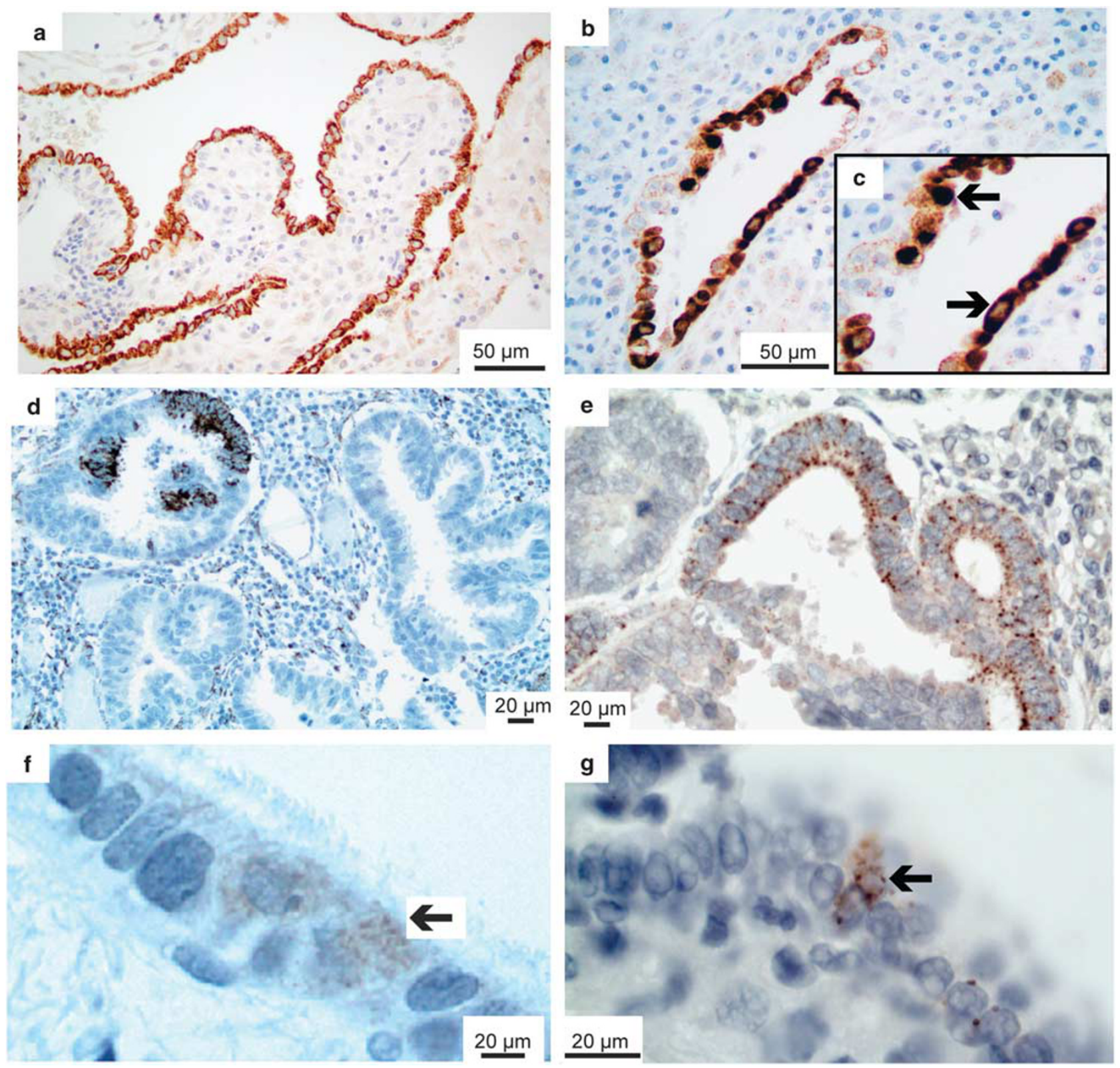

Figure 3 Histopathological and molecular features of HPV infection in the gravid and non-gravid endometrium. (a) HPV L1 IHC endometrium to illustrate HPV positivity in the decidualised epithelial cytoplasm. (b) HPV DNA CISH of the decidualised endometrium to illustrate HPV positivity. (c) Insert, higher power HPV DNA CISH endometrium to illustrate HPV positivity within epithelial cytoplasm (arrow) and nuclei (arrow). (d) HPV L1 IHC in non-gravid non-neoplastic endometrium amongst dysplastic endometrial glands. Negative HPV staining in glandular dysplasia, but positive staining in remnant non-neoplastic endometrial epithelium. (e) HPV DNA CISH in nongravid non-neoplastic endometrium amongst endometrial carcinoma. Negative HPV staining in glandular dysplasia but positive staining in remnant non-neoplastic endometrial epithelium. (f) Small foci of positive HPV L1 IHC in non-gravid Fallopian tube epithelium. (g) Corresponding focus of positive HPV DNA CISH in non-gravid Fallopian tube epithelium as illustrated in F above. CISH, chromogenic in situ hybridization; HPV, human papilloma virus; IHC, immunohistochemistry.

and d). HPV-SV samples subjected to CISH analysis and were predominantly cytoplasm positive for high-risk HPV type $(98 \%, 54 / 55)$.

\section{HPV-related Histopathological Subgroups Associated with Specific Clinical Features}

Pairwise comparisons demonstrated significant differences between HPV positive histopathological subtypes and pregnancy complications. Pregnancy complications correlating with HPV positivity or with the HPV histopathological subtype are given in Table 3. HPV was found in $84 \%(74 / 88)$ pre-term, $76 \%(55 / 72)$ of the FGR, $81 \%(13 / 16)$ of the intrauterine fetal death, $92 \%(23 / 25)$ of acute chorioamnionitis, $95 \%(42 / 44)$ of diabetes, and $100 \%$ preeclampsia (20/20) cases. HPV positive cases overall had borderline mean preterm gestational age (mean $36 \cdot 9$ weeks, $95 \%$ CI $36 \cdot 2-37 \cdot 5$ ), that was significantly lower compared with the HPV negative group (mean 

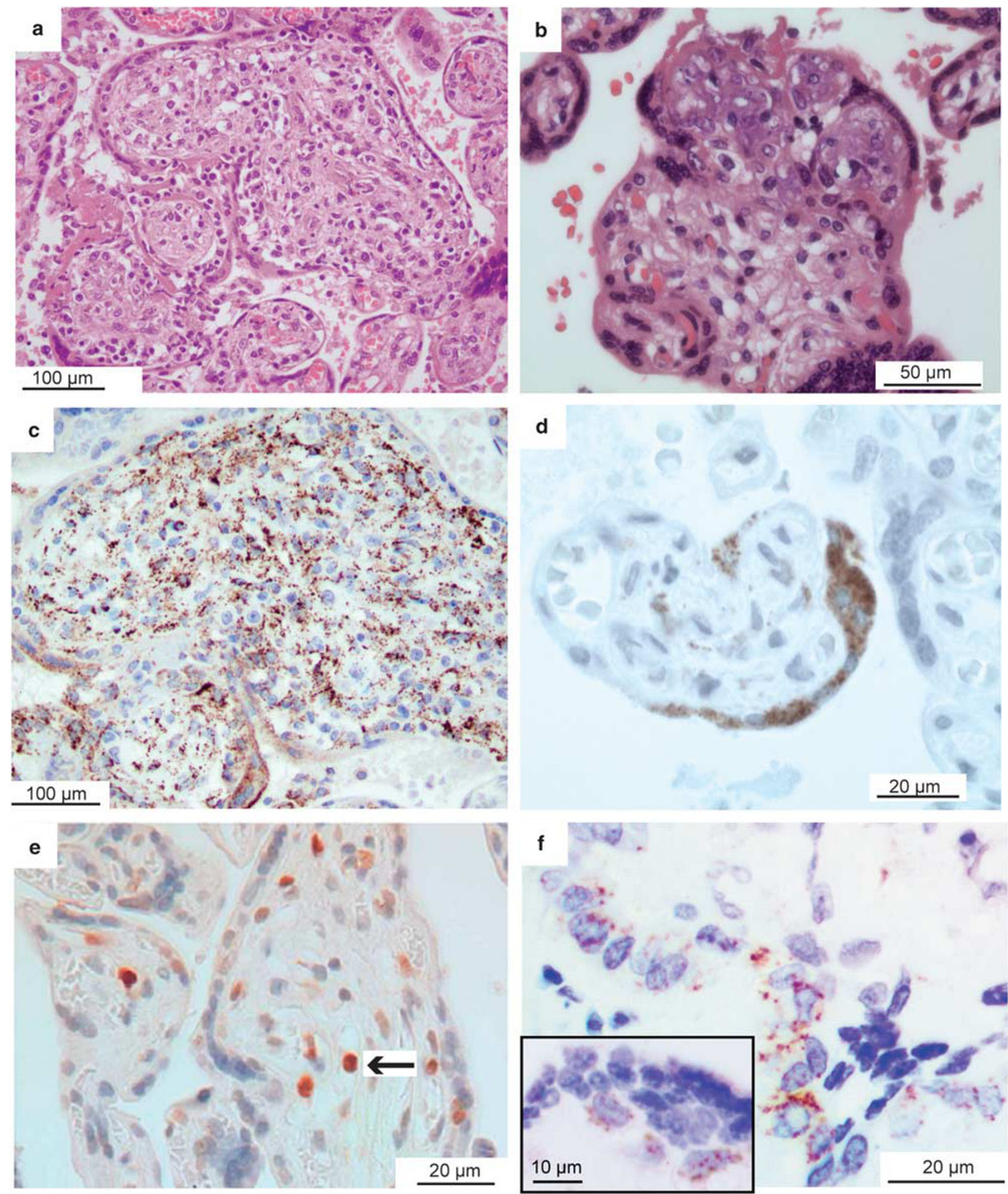

Figure 4 HPV-related lymphohistiocytic villitis subgroup (HPV-LHV) histopathology and molecular features. (a) H\&E low power of aggregated villi, showing syncytiotrophoblast loss, perivillous fibrin, and lymphocytic infiltration, otherwise typical of a villitis of unknown etiology, with no viral inclusions identified histopathologically, positive viral cultures/PCR, or positive maternal serology clinically. (b) H\&E higher power villous lesion with associated perivillous fibrin, minimal lymphocytic infiltration, and, fibrosis and vascular obliteration, especially in the upper part of the villus. (c) Low power HPV L1 IHC of same area as (a) above to illustrate HPV L1 capsid protein in aggregated villi. (d) Higher power HPV L1 IHC to illustrate HPV L1 capsid protein in the syncytiotrophoblast cytoplasm and smaller amounts in the underlying stroma to the left. (e) Gamma H2AX IHC positivity in villous stromal cells (arrow) in HPV-LHV case. (f) HPV DNA CISH (top and bottom panel) to illustrate diffuse HPV high-risk DNA positivity in the syncytiotrophoblast. CISH, chromogenic in situ hybridization; H\&E, hematoxylin and eosin stain; IHC, immunohistochemistry. 

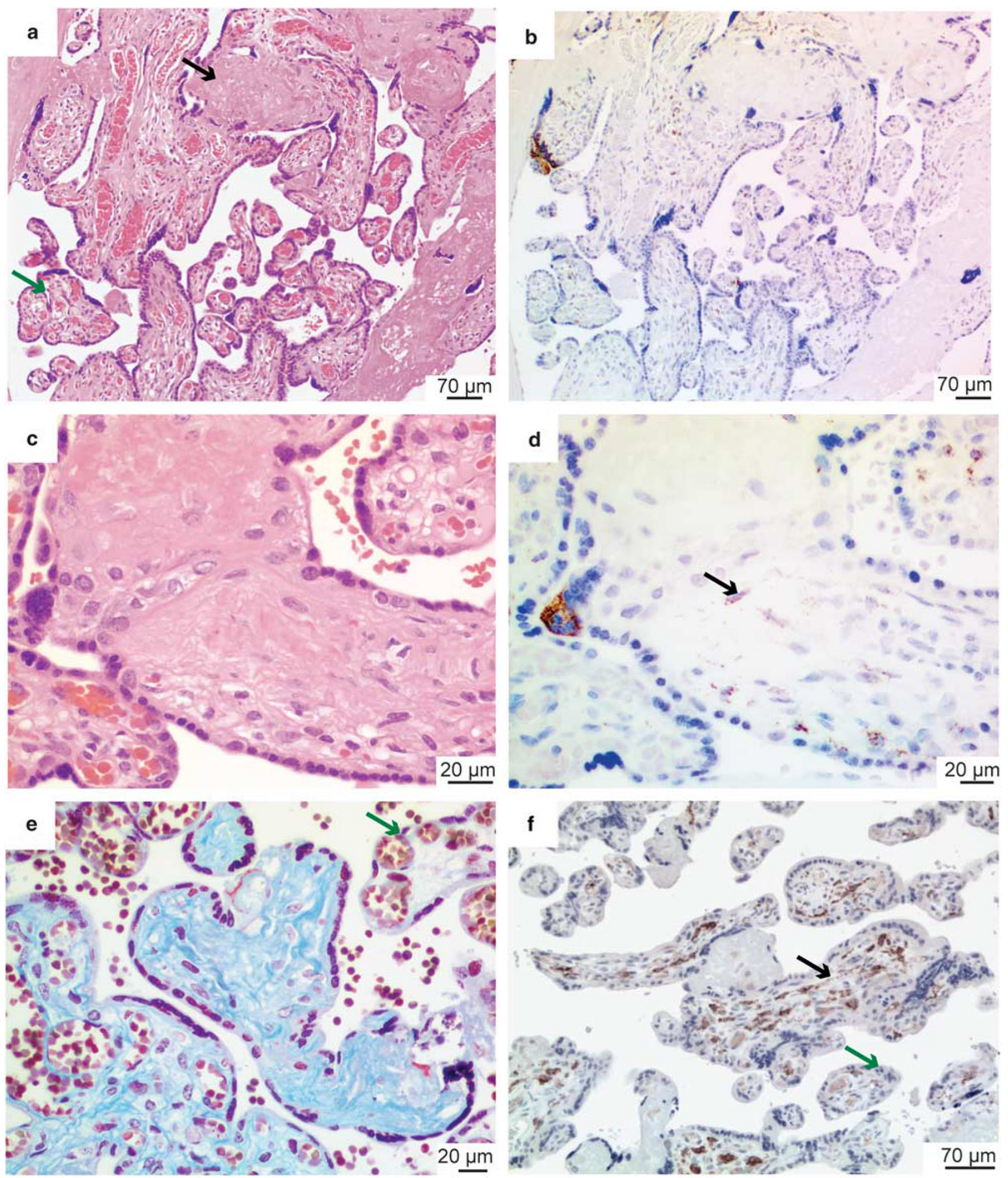

Figure 5 HPV-related sclerosing villitis (HPV-SV) histopathology and molecular features. (a) H\&E low power to show scattered partially or completely sclerosed villous (black arrow) with minimal infiltrating lymphocytes adjacent to normal well vascularized villous (green arrow). (b) HPV L1 IHC low power to illustrate HPV L1 capsid protein in villous stromal cells. (c) H\&E high power to show scattered partially or completely sclerosed villous with minimal infiltrating lymphocytes adjacent to a normal well vascularized villous (bottom). (d) HPV L1 IHC high power to illustrate HPV L1 capsid protein in villous stromal cells (black arrow) and syncytiotrophoblast cytoplasm in a sclerosed villous and no HPV L1 capsid protein in a non-sclerosed villous (bottom). (e) Martius Scarlet Blue staining to illustrate increased collagen (blue) in a sclerosed villous compared with a non-sclerosed villous (green arrow). (f) CD163 IHC to illustrate increased CD163 positive cells in a sclerosed villous (black arrow) compared with a non-sclerosed villous (green arrow). H\&E, hematoxylin and eosin stain; HPV, human papilloma virus; IHC, immunohistochemistry. 
38.4, 95\% CI 37.4-39.2, $P=0.02$ and Table 3). HPV was more frequent in the pre-term cohort (odds ratio $2 \cdot 13$, CI $1 \cdot 1-4 \cdot 0, P=0.018)$, and this was most evident in the HPV-LHV group with prematurity in $51 \%$ of cases (18/35) (odds ratio $5 \cdot 44$, CI $2 \cdot 2-13 \cdot 0$, $P<0 \cdot 001)$, whereas only $16.5 \%(14 / 85)$ of the HPV negative cases were premature (Table 3). Fetalgrowth restriction was prevalent in the HPV-LHV group with $54 \%$ of cases (19/35) with FGR. The mean personalized fetal growth centile was the lowest in the HPV-LHV group (mean 18.7, Table 3) and highest in the HPV-SV group (mean 48.7), compared with the HPV negative (mean, 33.3) and HPV-decidua groups (mean, 35.6) $(P=0.02)$. Acute chorioamnionitis was found more frequently in the HPV positive than in the HPV negative group (odds ratio $5 \cdot 54$, CI $1 \cdot 2-24 \cdot 3, P=0.02$ ), being most frequent in the HPV-decidua subgroup $(76 \%, 19 / 25$, $P=0.04)$.

\section{Diabetes and Pre-eclampsia}

HPV positive cases were more frequent in preeclampsia and diabetes cases (OR was 8.4, CI 1.9-51.1, $P<0.05)$. Women with either diabetes or pre-eclampsia were represented by particular HPV-related histopathological groups, HPV-SV and HPV-LHV respectively. Almost half (49\%) of the HPV-SV group were from diabetic mothers. All of the women with pre-eclampsia $(20 / 20)$ were highrisk HPV positive, and all but one were found in either the HPV-decidua $(8 / 20,40 \%)$ or HPV-LHV $(11 / 20,55 \%)$ groups. Pre-eclampsia populated a third $(11 / 35,31 \%)$ of the HPV-LHV cases.

\section{Cervical HPV Smear History Correlated with Placental HPV}

Cervical smear histories were available for $71 \%$ (241/339) women in our cohort from 1993 to 2014, and this included results for all of the women in the placental HPV negative group. This negative group comprised a total of 333 smear results (mean 3.9 smear results/woman) for up to 15 years before the index pregnancy. At least one HPV-related positive smear result before index pregnancy was found in $9.4 \%(8 / 85)$ women. In the placental HPV positive group overall, cervical smear results were available for $81 \%(207 / 253)$ women, with total of 871 smear results (mean 4.2 results/woman), available for up to 15 years before pregnancy. At least one HPV-related positive smear result was found in 33\% (69/207) of women before the index pregnancy, compared with the negative group $(P=0.0001)$. Thus, cervical HPV infection was correlated with placental HPV results.

\section{Discussion}

We conducted a cross-sectional study to determine the HPV infection status of 339 placentae using five 
independent methods and identified HPV in $75 \%$ (253/339) of cases. Three immunohistopathological patterns of HPV infection emerged, and these varied with specific pregnancy complications and their correlation with HPV cervical smear results. Furthermore, higher rates of FGR, prematurity, and acute chorionamnionitis were associated with particular immunohistopathological findings (Table 3). Previous studies have reported much lower rates of placental infection with HPV ${ }^{2,5,6}$ but this may reflect sampling of a small area of villous tissue, which has patchy HPV presence, in preference to the more uniformly-infected decidua.

We designated the most prevalent immunohistopathological pattern HPV-decidua, in which HPV was detected in the decidua basalis and endometrium. Histopathological features were within those accepted as normal on H\&E. That this group was associated with acute chorioamnionitis is consistent with a second trimester study wherein PCR identified HPV DNA more frequently in acute chorioamnionitis than in controls. ${ }^{7}$ Furthermore, cervical HPV infection impairs the physiological protective capacity of the uterine cervix. ${ }^{30}$ Studies employing in situ hybridization have detected HPV DNA in non-neoplastic endometrium in $19.6^{31}$ and $60 \% 32$ of biopsies. It is possible that initial infection of the endometrium is facilitated by regular menstrual shedding (akin to wounding), whereas the lack of menstrual shedding, endometrial decidualisation, and immune suppression during pregnancy contributes to HPV persistence and growth. Thus the endometrium could represent a reservoir of HPV infection.

HPV-associated lymphohistiocytic villitis was defined by patchy syncytiotrophoblast HPV positivity with lymphocytic and macrophage villous infiltration in addition to infection of the decidual tissue described above. Some of these cases were diagnosed as VUE; a condition for which no infectious agent has been identified. ${ }^{33,34}$

The clinical impact of HPV-LHV was suggested by higher rates of FGR, preterm delivery, and stillbirth (Table 3), as occurs with other causes of infectious villitis. The syncytiotrophoblast is the main functional cellular component of the placenta and active inflammation interferes with its function and impinges on pregnancy success. ${ }^{35}$ Idiopathic chronic inflammation has also been reported in $20 \%$ of preterm pre-eclampsia cases, ${ }^{36}$ and we identified pre-eclampsia in $31 \%(11 / 35)$ of HPV-LHV cases in this cohort. All cases of pre-eclampsia (20/20) were infected with a high-risk HPV type. Our findings support the proposal that HPV infection contributes to the pathogenesis of pre-eclampsia, ${ }^{37-39}$ and alters overall inflammatory marker expression in pregnancy. ${ }^{40,41}$ In a cell culture setting, HPV infection impairs trophoblast cell function by inducing trophoblast cell death and defective endometrial cell recognition. ${ }^{42}$ Extravillous trophoblast invasion would impede the quality of implantation. ${ }^{43}$ The global incidence of pre-eclampsia has increased in recent years, ${ }^{44}$ but a decrease could be expected with the impact of HPV vaccination.

The HPV-sclerosing villitis pattern had minimal detectable HPV-L1 IHC in villous trophoblast and minimal lymphocytic infiltration (Figure 5), and $49 \%(27 / 55)$ of diabetic cases exhibited this pattern. Surprisingly, complication rates were similar to or lower than the other two HPV-related histopathological patterns, and we suggest that gestational diabetes may have been selected for at an evolutionary level in the face of widespread HPV infection. That increased numbers of villous macrophages were present may contribute to findings of higher numbers of CD163 macrophages in diabetic and high BMI-associated placentae. ${ }^{45}$ This is consistent with recent work examining the infected uterine cervix, whereby HPV induces a switch from the M1 to M2 (CD163 positive) macrophage type. ${ }^{46}$ That this group represents a recovered HPV-LHV group in a state of resolving inflammation and scarring seems plausible.

This study is biased towards complicated pregnancies as the prevalence of prematurity, FGR, and fetal demise are over-represented, and therefore, this population does not reflect the community at large. Of note, however, no statistically significant difference was identified for mean maternal age, BMI, gestational age, or personalized growth centile between HPV negative and HPV positive groups.

From a treatment perspective, heparin has been administered to problematic pregnancies. The effect of heparin treatment in assisting some pregnancies could lie in its ability to block the heparin binding site of HPV, ${ }^{47}$ and HPV status may provide clarity to the heparin therapy debate. ${ }^{48}$ Similarly, salicylic acid is widely prescribed and appears effective in pre-eclamptic pregnancies. ${ }^{49}$ Salicyclic acid is also used as an inexpensive treatment for cutaneous warts, possibly affecting HPV E6 and E7 protein action on cyclooxygenase- 2 transcription. ${ }^{50}$

Infection with HPV has been regarded as restricted to keratinocytes, and that both HPV L1 IHC and CISH were detected HPV in the cytoplasm of trophoblast initially raised concerns that this was a non-specific reaction. However, strong cytoplasmic L1 capsid protein mRNA expression has also been reported in a trophoblast cell culture experimentally infected with HPV. ${ }^{20}$ Moreover, cytoplasmic localization of HPV has been reported using both HPV L1 IHC and $\mathrm{CISH}^{25,27,51-53}$ and this pattern may be characteristic of HPV infection in the trophoblast. We also observed an appropriate host response of DNA damage/repair and p53 activation, which was consistent with that previously described for papillomavirus infection. ${ }^{29}$

To the best of our knowledge, this is the first study to describe in situ morphology of placental HPV infection and associated adverse clinical events, although further investigation is required to prove HPV is the etiologic agent. However, the popular 
assertion that HPV infection is of no clinical consequence in pregnancy maybe incorrect in light of our findings. Whether HPV contributes to other obstetric complications is also worthy of investigation.

Our study provides additional support for HPV vaccination. The possibility that HPV contributes to or causes pregnancy complications, such as preeclampsia, raises the prospect that HPV vaccination will not only prevent cervical cancer, but will have a wider impact preventing pregnancy complications.

\section{Acknowledgments}

The Families, Core and LMC Midwives, and Resident staff at Queen Mary Hospital, Dunedin Hospital, New Zealand, who donated and helped to collect placentae are thanked without reservation. Otago University Medical students Flora Kwon, Sally Ma, Lydia Park, and Raymond Chan are thanked for their assistance during Summer Studentships from the Otago Medical Research Foundation. For collection assistance we also thank Southern Community Laboratories. We are grateful to the Director of the Otago University Dunedin School of Medicine Histology Unit, Amanda Fisher, and her team for technical expertise. Allan Mitchell and Gillian Grayson at the Otago Electron Microscopy Unit are thanked for their ultrastructure assistance. Dr Chris Frampton is gratefully acknowledged for his statistical expertise and guidance in the preparation and reporting of this study. This project was funded by the New Zealand National Center for ExcellenceGravida, The Healthcare Otago Charitable Trust, and Matariki Diagnostics. With great sadness we communicate the premature passing of our co-author and inspirational friend Bill Clow.

\section{Disclosure/conflict of interest}

The authors declare no conflict of interest.

\section{References}

1 Herrington CS, Coates PJ, Duprex WP. Viruses and disease: emerging concepts for prevention, diagnosis and treatment. J Pathol 2015;235:149-152.

2 Hahn HS, Kee MK, Kim HJ et al. Distribution of maternal and infant human papillomavirus: risk factors associated with vertical transmission. Eur J Obstet Gynecol Reprod Biol 2013;169:202-206.

3 Koskimaa HM, Waterboer T, Pawlita $\mathrm{M}$ et al. Human papillomavirus genotypes present in the oral mucosa of newborns and their concordance with maternal cervical human papillomavirus genotypes. J Pediatr 2012;160:837-843.

4 Park H, Lee SW, Lee IH et al. Rate of vertical transmission of human papillomavirus from mothers to infants: relationship between infection rate and mode of delivery. Virol J 2012;9:80.
5 Eppel W, Worda C, Frigo P et al. Human papillomavirus in the cervix and placenta. Obstet Gynecol 2000;96:337-341.

6 Kim YH, Park JS, Norwitz ER et al. Genotypic prevalence of human papillomavirus infection during normal pregnancy: a cross-sectional study. J Obstet Gynaecol Res 2014;40:200-207.

7 Srinivas SK, Ma Y, Sammel MD et al. Placental inflammation and viral infection are implicated in second trimester pregnancy loss. Am J Obstet Gynecol 2006;195:797-802.

8 Malhomme O, Dutheil N, Rabreau M et al. Human genital tissues containing DNA of adeno-associated virus lack DNA sequences of the helper viruses adenovirus, herpes simplex virus or cytomegalovirus but frequently contain human papillomavirus DNA. J Gen Virol 1997;78:1957-1962.

9 Hermonat PL, Kechelava S, Lowery CL et al. Trophoblasts are the preferential target for human papilloma virus infection in spontaneously aborted products of conception. Hum Pathol 1998;29:170-174.

10 Cho G, Min KJ, Hong HR et al. High-risk human papillomavirus infection is associated with premature rupture of membranes. BMC Pregnancy Childbirth 2013;13:173.

11 Gomez LM, Ma Y, Ho C et al. Placental infection with human papillomavirus is associated with spontaneous preterm delivery. Hum Reprod 2008;23:709-715.

12 Zuo Z, Goel S, Carter JE. Association of cervical cytology and HPV DNA status during pregnancy with placental abnormalities and preterm birth. Am J Clin Pathol 2011;136:260-265.

13 McDonnold M, Dunn H, Hester A et al. High-risk human papillomavirus at entry to prenatal care and risk of preeclampsia. Am J Obstet Gynecol 2014;210: 138 e1-e5.

14 Pao CC, Hor JJ, Wu CJ et al. Human papillomavirus type 18 DNA in gestational trophoblastic tissues and choriocarcinomas. Int J Cancer 1995;63:505-509.

15 Armbruster-Moraes E, Ioshimoto LM, Leao E et al. Detection of human papillomavirus deoxyribonucleic acid sequences in amniotic fluid during different periods of pregnancy. Am J Obstet Gynecol 1993;169:1074.

16 Rombaldi RL, Serafini EP, Mandelli J et al. Transplacental transmission of Human Papillomavirus. Virol J 2008;5:106.

17 Lee SM, Park JS, Norwitz ER et al. Risk of vertical transmission of human papillomavirus throughout pregnancy: a prospective study. PloS one 2013;8:e66368.

18 Liu Y, You H, Chiriva-Internati M et al. Display of complete life cycle of human papillomavirus type 16 in cultured placental trophoblasts. Virology 2001;290:99-105.

19 You H, Liu Y, Agrawal N et al. Infection, replication, and cytopathology of human papillomavirus type 31 in trophoblasts. Virology 2003;316:281-289.

20 You H, Liu Y, Agrawal N et al. Multiple human papillomavirus types replicate in $3 \mathrm{~A}$ trophoblasts. Placenta 2008;29:30-38.

21 Phillips JB, Billson VR, Forbes AB. Autopsy standards for fetal lengths and organ weights of an Australian perinatal population. Pathology 2009;41:515-526.

22 Holzman C, Lin X, Senagore P et al. Histologic chorioamnionitis and preterm delivery. Am J Epidemiol 2007;166:786-794.

23 Slatter TL, Park L, Anderson K et al. Smoking during pregnancy causes double-strand DNA break damage to the placenta. Hum Pathol 2014;45:17-26. 
24 Wititsuwannakul J, Klump VR Jr, McNiff JM et al. Detecting HPV in cutaneous lesions using anti-HPV antibody immunohistochemistry. Am J Dermatopathol 2013;35:327-331.

25 Birner P, Bachtiary B, Dreier B et al. Signalamplified colorimetric in situ hybridization for assessment of human papillomavirus infection in cervical lesions. Mod Pathol 2001;14:702-709.

26 Hass R, Sohn C. Increased oxidative stress in preeclamptic placenta is associated with altered proteasome activity and protein patterns. Placenta 2003;24:979-984.

27 Iwasaki T, Sata T, Sugase M et al. Detection of capsid antigen of human papillomavirus (HPV) in benign lesions of female genital tract using anti-HPV monoclonal antibody. J Pathol 1992;168:293-300.

28 Syrjanen K, Vayrynen M, Mantyjarvi R et al. Electron microscopy in assessment of the biological behavior of human papillomavirus infections in the uterine cervix. Neoplasma 1986;33:493-505.

29 Park JW, Nickel KP, Torres AD et al. Human papillomavirus type 16 E7 oncoprotein causes a delay in repair of DNA damage. Radiother Oncol 2014;113: 337-344.

30 Cardenas I, Mor G, Aldo $\mathrm{P}$ et al. Placental viral infection sensitizes to endotoxin-induced pre-term labor: a double hit hypothesis. Am J Reprod Immunol 2011;65:110-117.

31 Karadayi N, Gecer M, Kayahan S et al. Association between human papillomavirus and endometrial adenocarcinoma. Med Oncol 2013;30:597.

32 Fujita M, Shroyer KR, Markham NE et al. Association of human papillomavirus with malignant and premalignant lesions of the uterine endometrium. Hum Pathol 1995;26:650-658.

33 Redline RW. Villitis of unknown etiology: noninfectious chronic villitis in the placenta. Hum Pathol 2007;38:1439-1446.

34 Boog G. Chronic villitis of unknown etiology. Eur J Obstet Gynecol Reprod Biol 2008;136:9-15.

35 Roescher AM, Timmer A, Erwich JJ et al. Placental pathology, perinatal death, neonatal outcome, and neurological development: a systematic review. PloS one 2014;9:e89419.

36 Salafia CM, Pezzullo JC, Lopez-Zeno JA et al. Placental pathologic features of preterm preeclampsia. Am J Obstet Gynecol 1995;173:1097-1105.

37 Redman CW, Sargent IL. The pathogenesis of preeclampsia. Gynecol Obstet Fertil 2001;29:518-522.

38 Schonkeren D, van der Hoorn ML, Khedoe $\mathrm{P}$ et al. Differential distribution and phenotype of decidual macrophages in preeclamptic versus controlpregnancies. Am J Pathol 2011;178:709-717.

39 Faas MM, Spaans F, De Vos P. Monocytes and macrophages in pregnancy and preeclampsia. Front Immunol 2014;5:298.

40 Sacks GP, Studena K, Sargent K et al. Normal pregnancy and preeclampsia both produce inflammatory changes in peripheral blood leukocytes akin to those of sepsis. Am J Obstet Gynecol 1998;179:80-86.

41 Kim SY, Romero R, Tarca AL et al. Methylome of fetal and maternal monocytes and macrophages at the fetomaternal interface. Am J Reprod Immunol 2012;68: 8-27.

42 You H, Liu Y, Carey MJ et al. Defective 3A trophoblastendometrial cell adhesion and altered 3A growth and survival by human papillomavirus type 16 oncogenes. Mol Cancer Res 2002;1:25-31.

43 Kwon JY, Romero R, Mor G. New insights into the relationship between viral infection and pregnancy complications. Am J Reprod Immunol 2014;71:387-390.

44 Ananth CV, Keyes KM, Wapner RJ. Pre-eclampsia rates in the United States, 1980-2010: age-period-cohort analysis. BMJ 2013;347:f6564.

45 Challier JC, Basu S, Bintein $\mathrm{T}$ et al. Obesity in pregnancy stimulates macrophage accumulation and inflammation in the placenta. Placenta 2008;29: 274-281.

46 Sanchez-Reyes K, Bravo-Cuellar A, Hernandez-Flores $\mathrm{G}$ et al. Cervical cancer cell supernatants induce a phenotypic switch from U937-derived macrophageactivated $\mathrm{m} 1$ state into $\mathrm{m} 2$-like suppressor phenotype with change in toll-like receptor profile. Biomed Res Int 2014;2014:683068.

47 Richards KF, Bienkowska-Haba M, Dasgupta J et al. Multiple heparan sulfate binding site engagements are required for the infectious entry of human papillomavirus type 16. J Virol 2013;87:11426-11437.

48 Potdar N, Gelbaya TA, Konje JC et al. Adjunct lowmolecular-weight heparin to improve live birth rate after recurrent implantation failure: a systematic review and meta-analysis. Hum Reprod Update 2013;19:674-684.

49 Mone F, McAuliffe FM. Low-dose aspirin and calcium supplementation for the prevention of pre-eclampsia. The Obstetrician \& Gynaecologist 2014;16:245-250.

50 Subbaramaiah K, Dannenberg AJ. Cyclooxygenase-2 transcription is regulated by human papillomavirus 16 E6 and E7 oncoproteins: evidence of a corepressor/ coactivator exchange. Cancer Res 2007;67:3976-3985.

51 Pannone G, Rodolico V, Santoro A et al. Evaluation of a combined triple method to detect causative HPV in oral and oropharyngeal squamous cell carcinomas: p16 Immunohistochemistry, Consensus PCR HPV-DNA, and In Situ Hybridization. Infect Agent Cancer 2012;7:4.

52 Handisurya A, Day PM, Thompson CD et al. Characterization of Mus musculus papillomavirus 1 infection in situ reveals an unusual pattern of late gene expression and capsid protein localization. J Virol 2013;87:13214-13225.

53 Dreier K, Scheiden R, Lener B et al. Subcellular localization of the human papillomavirus 16 E7 oncoprotein in CaSki cells and its detection in cervical adenocarcinoma and adenocarcinoma in situ. Virology 2011;409:54-68. 